\title{
Fisiopatología de la sepsis por gram positivos
}

\author{
Yardany Méndez Fandiño ${ }^{1}$, María Claudia Barrera C. ${ }^{2}$
}

Médico Internista, Epidemiólogo. MSc. Investigación Clínica Yardanymendezf@yahoo.es

2 Médico general, Microbióloga industrial.mcbsarai@yahoo.com
Correspondencia: Dra. María Claudia Barrera maria-barrera@juanncorpas.edu.co

Como citar: Méndez Y, Barrera MC. Fisiopatología de la sepsis por gram positivos. Cuarzo 2016; 21 (1): 51-65.

Recibido: 25 de febrero de 2016. Aceptado: 1 de junio de 2016. Publicado: 30 de junio de 2016.

Licencia creative commons

\section{Resumen}

Las bacterias gram positivas vienen cobrando importancia como agentes etiológicos de la sepsis siendo algunos de principales representantes Staphylococcus aureus, las cepas de S.aureus meticilino resistentes (MRSA del inglés) y el Streptococcus pyogenes o también llamado Streptococcus del grupo A invasivo (GAS). Dado que en su estructura celular presentan diversas moléculas que pueden ser reconocidas como patrones moleculares asociados a patógenos (PAMPs) como son el peptidoglicano (PNG) el ácido teicoico (LTA), las lipoproteínas; y otras que activan directamente el sistema inmune adaptativo como son los Superantígenos; los pacientes infectados pueden exponerse de manera simultánea a una respuesta inmune amplificada de manera sinérgica entre todos estos tipos de antígenos, que a través de vías de señalización intracelular desencadenarán la transcripción de genes codificadores de citocinas pro inflamatorias como el TNF $\alpha$, la IL-1 $\beta$, la IL-6, el INF $\gamma$, IL-8, IL-18, IL-2, IL-12, IL-10 que darán lugar a muchas de las manifestaciones clínicas de la sepsis y se vienen asociando como predictores del pronóstico de esta junto a otros marcadores moleculares de la misma.

PALABRAS CLAVE: Sepsis, Bacterias Gram positivas, Molecular, Factores de virulencia, Patología clínica.

Towards an educational proposal to promote undergraduates' professional identity

Gram positive bacteria are becoming important as etiological agents of sepsis, with some of the main representatives of Staphylococcus aureus, strains of S. aureus methicillin resistant (MRSA) and the Streptococcus pyogenes or also Streptococcus group A invasive (GAS). Since in their cellular structure they present several molecules that can be recognized as molecular pathogen associated pathogens (PAMPs) such as peptidoglycan (PNG), teicoico acid (LTA), lipoproteins; and others that directly activate the adaptive immune 
system such as Superantigens; infected patients can be exposed simultaneously to a synergistically amplified immune response among all these types of antigens, which through intracellular signaling pathways will trigger the transcription of genes encoding pro-inflammatory cytokines such as TNF $\alpha$, IL-1 $\beta$, IL-8, IL-12, IL-12, IL-10, IL-10, which will lead to many of the clinical manifestations of sepsis and are associated as predictors of prognosis of this with other molecular markers of the same

KEYWORDS: Sepsis, Gram-Positive Bacteria, Molecular, Virulence Factors, Clinical Pathology.

\section{Introducción}

Durante mucho tiempo se consideró que los principales microorganismos que causaban la sepsis eran bacterias gram negativas, sin embargo, en los últimos 25 años se ha evidenciado que las bacterias gram positivas vienen cobrando importancia como agentes principales de la sepsis. En Estados Unidos se han encontrado cerca de 200 000 casos de sepsis por gram positivos frente a aproximadamente 150000 casos de sepsis de gram negativos, siendo sus principales representantes Staphylococcus aureus y Streptococcus pyogenes, quienes tanto en países en desarrollo como en países industrializados, acompañadas de las Enterobacteriaceas sp, son la principal causa de sepsis tardía en neonatos. Adicionalmente, en los últimos 20 años, se ha hecho protagonista de sepsis el Streptococcus pyogenes del grupo A invasivo (GAS), considerado un importante problema de epidemiología mundial y responsable en un $10-16 \%$ de la sepsis en infecciones en las que es su principal agente etiológico como infecciones puerperales, artritis séptica, fascitis necrotizante, celulitis, entre otras; y $20 \%$ de la sepsis en las admisiones en unidades de cuidados intensivos en casos de infección invasiva por este microorganismo (1-4).

\section{Bacterias Gram positivas: Estructura molecular antigénica}

Las bacterias grampositivas cuentan en su estructura con un gran arsenal de factores de virulencia que facilitan la adhesión tisular, evasión inmune y lesión celular del huésped que finalmente llevarán a la inflamación, alterarán la función de las células inmunes, alteran la coagulación y comprometerán la integridad de la vasculatura. Dentro de este arsenal se encuentran los componentes de su pared celular incluido el peptidoglicano (PGN), que, en estas, a diferencia de las gram negativas, es más grueso; y el ácido lipotéicoico (LTA), ambos pertenecen a los llamados patrones moleculares asociados a patógenos (PAMPs), sin embargo, el LTA se ha comparado en su efecto antigénico con el LPS de las bacterias gram negativas. Sumados al LTA y el PNG, recientemente se ha centrado la atención en las lipoproteínas bacterianas involucradas en procesos como son la nutrición, la resistencia antibiótica, secreción de proteínas, biogénesis de la pared celular y adhesión a matriz extracelular y tejidos del huésped. Éstas son sintetizadas como pre - lipoproteínas las cuales son modificadas mediante dos enzimas altamente conservadas en las bacterias: la Lgt que les transfiere moléculas de diacilglicerol, luego de lo cual son traslocadas a través de la membrana citoplasmática donde por acción de la segunda enzima Lsp se rompe el enlace entre el aminoácido de la primera posición (glicina) y el residuo de cisteína de la lipoproteina convirtiéndola en la lipoproteína madura que logra ser reconocida como PAMPs (5-7).

El Peptidoglicano, que en las bacterias gram positivas llega a ser de 40 a 80 capas, es considerado una gran macromolécula que forma un sáculo alrededor de la célula bacteriana y está compuesto por cadenas con enlaces beta 1-4 entre moléculas de glicanos alternadas del tipo Nacetilglucosamina (GlcNAc) y Ácido N acetilmurámico (MurNAc). A éste último se unen, a través de grupos lactilo, cadenas de pentapéptidos constituidos principalmente por la secuencia L- Alanina - D glutamina - Ácido mesodiaminopimélico (mDAP) (o L-Lisina) - D alanina - D alanina. A esta pared de peptidoglicano se ancla el ácido lipoteicoico definido como un polímero soluble de unidades repetidas de glicerolfosfato o ribitolfosfato que se une a la membrana mediante un enlace glicolípido o unido covalentemente al ácido Nacetilmurámico del PGN, y en tal caso hablamos de ácido teicóico (WTA). De acuerdo a su estructura química hay 5 tipos de LTA, el tipo I es el mejor estudiado y se halla en Staphylococcus aureus, Bacillus subtillis, Streptococcus agalactiae, Streptococcus pyogenes y Listeria monocitogenes, el tipo II, contiene en Lactococcus garviaea, el tipo III en Clostridiuim inccocuum, el tipo IV en Streptococcus pneumoniae, y el tipo $\mathrm{V}$ en Clostridium difficile (Figura 1). La modificación del 
LTA con adición de azucares como $\alpha$-galactosa o N- acetil glucosamina, así como la modificación de la cadena peptídica o de las moléculas de glicanos 8NAM - NAG) del PNG, son algunos de los mecanismos de evasión del sistema inmune con que cuentan las bacterias gram positivas (6-9).
En el caso del Streptococcus pyogenes del grupo A, asociado a un amplio rango de enfermedades que van desde impétigo, faringitis aguda y sus secuelas como son la fiebre reumática postestreptococica, enfermedad cardiaca reumática y la glomerulonefritis aguda, hasta enfermedades invasivas como fascitis necrotizante y síndrome de

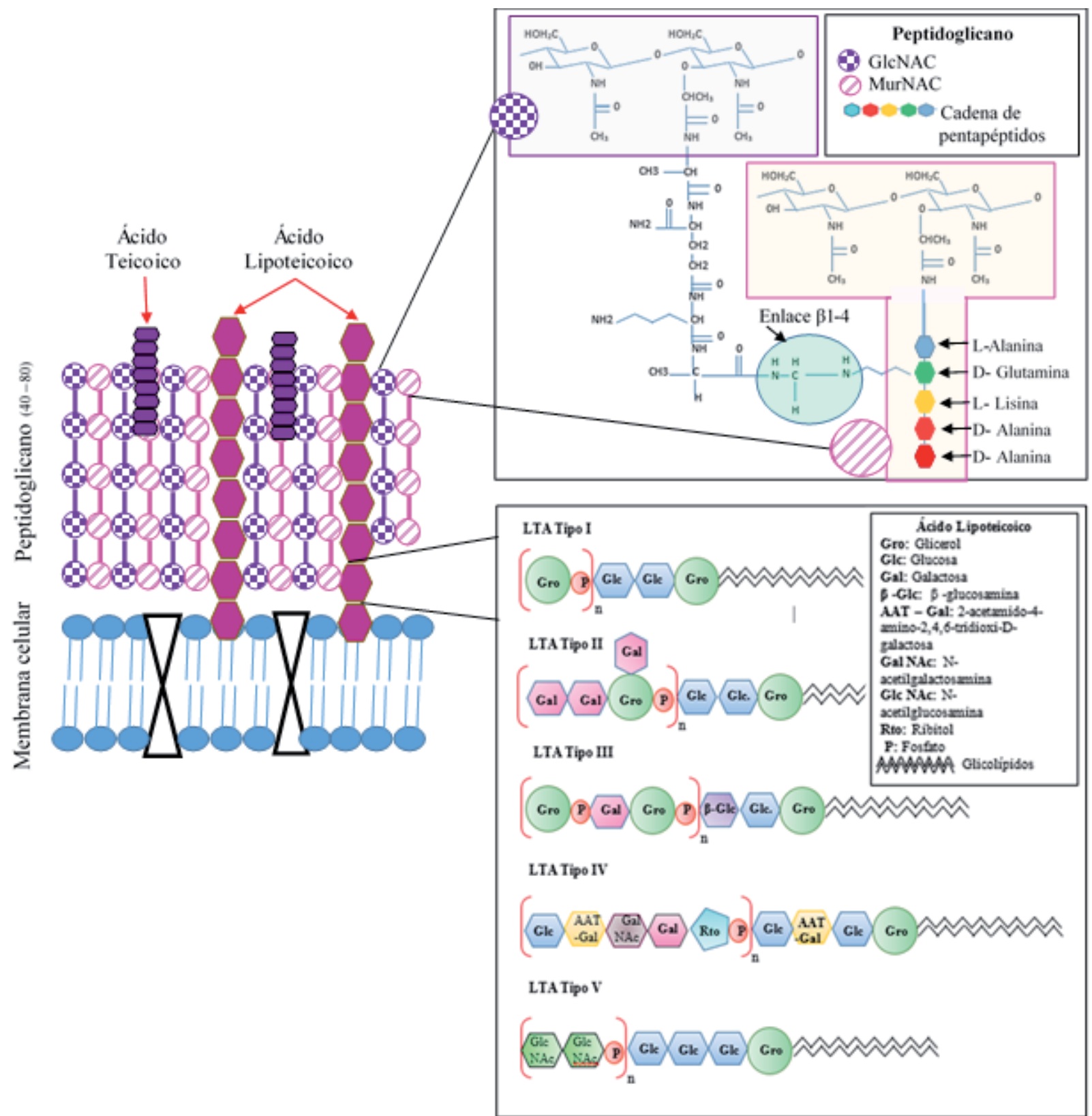

FIGURA 1. Estructura del Peptidoglicano y el Ácido Lipoteicoico en las bacterias gram positivas

Fuente: Construida por los autores con base en las halladas en: Kang SS, Sim JR, Yun CH, Han SH. Lipoteichoic acids as a major virulence factor causing inflammatory responses via Toll-like receptor 2. Arch Pharm Res [internet]. 2016:1-11 [consultado 2016 Agosto 20]. DOI:10.1007/s12272016-0804-y; y Malanovic N, Lohner K. Gram-positive bacterial cell envelopes: The impact on the activity of antimicrobial peptides. Biochim Biophys Acta. 2016;1858(5):936-46. 
shock tóxico estreptocócico muchas capaces de cursar con cuadros sépticos severos $(10,11)$; se reconoce que es capaz de producir gran variedad de factores de virulencia, más que muchos otros patógenos; que participan en su adhesión y colonización haciendo de este un patógeno exitoso. Dentro de estos se encuentran las estreptolisinas, estreptocinasas, proteinasas, esterasas, inhibidor del complemento, superoxido dismutasa, hialuronidasas, el petidoglicano, el ácido teicoico, y en especial el amplio número de pilis que exhiben en su superficie y la proteína M de superficie celular (Figura 2) $(11,12)$.

Los pilis de la superficie, detectados hasta 2005, son filamentos constituidos por cadenas simples protéicas unidas con enlaces covalentes que conforman una pilina mayor (BP del inglés) que se polimeriza en uno de sus extremos; dos pilinas auxiliares que funcionan como adhesinas (AP-1 en inglés) y una proteína adaptadora que une la base del pili, mediante un enlace covalente al peptidoglicano de la pared celular. Esta estructura es altamente variable en esta especie y hoy se sabe que constituye el blanco del sistema de clasificación de Lancefield empleado por mucho tiempo para subclasificar a estas bacterias; adicionalmente se sabe que esta estructura es codificada en la región altamente variable de su genoma, el locus codificador del antígeno $\mathrm{T}$, proteína de unión a colágeno y fibronectina (FCT del inglés), en la que también es codificado el antígeno T6 y las adhesinas de superficie que confieren a este microorganismo la capacidad de unirse al colágeno humano y la fibronectina y participa activamente en su patogénesis facilitando su adhesión a nivel del epitelio faríngeo y de los queratinocitos, especialmente las AP-1. Aunque se desconoce el receptor específico de esta estructura, se cree que es a través de regiones conservadas del colágeno tipo I, la glicoproteina de la saliva gp340, y se ha asociado a casos de cepas con hipervirulencia que promueven el reclutamiento de neutrófilos, formación de trampas extracelulares de neutrófilos (del inglés NETs) y participan en el progreso hacia sepsis asociada a este microorganismo $(11,13,14)$.

La Proteína M, el mayor determinante de virulencia en este microorganismo, media la unión a las células del huésped y la resistencia a la fagocitosis mediada por leucocitos polimorfonucleares al no existir anticuerpos específicos. Existen más de 200 serotipos de esta proteína en virtud de la región N- terminal de la misma constituida por cerca de 50 aminoácidos (aa) cuyo mecanismo de variabilidad aún es desconocido. Se sabe que en su estructura consta de 4 secuencias repetidas, la A con 14 aa, la $\mathrm{B}$ con 25 aa, la $\mathrm{C}$ con 2.5 bloques de 42 aa cada uno y la $\mathrm{D}$ que en realidad son cuatro pequeñas repeticiones similares entre sí y que su anclaje a la pared celular se da a través del extremo C- terminal en el que se ha identificado una secuencia común denominada LPXTG la cual es compartida con otras proteínas de superficie estreptocócica $(11,15)$.

Las especies invasivas de este microorganismo, que son las asociadas a sepsis y síndrome de shock tóxico (STSS) son los serotipos M1 y M3 responsables del 50\% de STSS en Europa y 30\% en Estados Unidos. La proteína $\mathrm{M}$ es codificada por el gen emm y se han identificado más de 200 secuencias diferentes. El serotipo M1 es el más asociado a enfermedades invasivas y en los últimos 30 años se ha diseminado el serotipo relacionado a este, llamado M1T1 definido como las cepas que contienen el bacteriófago que codifica el factor de virulencia extracelular estreptodornasa D (Sda 1) y la exotoxina tipo A (SPE a), ambos factores aumentan la capacidad de diseminación y virulencia del microorganismo, la Sda1 le permite a la bacteria escapar de la muerte mediada por neutrófilos persistiendo en el sitio de la infección inicial ya que degrada mediante una DNasa (DNasa Sda 1) las NETs. Sumada a esta proteína, las cepas invasivas cuentan con un sistema de mutaciones espontaneas en un grupo de genes denominados CovRS, que potencian su virulencia. Este grupo de genes constituye el operon que codifica para la cápsula de ácido hialurónico que aísla la bacteria del medio evadiendo el sistema inmune; la estreptolisina $\mathrm{O}$ (SLO) que entre otras funciones induce la apoptosis de las células epiteliales, neutrófilos y macrófagos; el inhibidor estreptocócico del complemento (SIC) que interfiere con la formación del complejo de ataque de membrana (MAC) al inhibir la unión del complejo del complemento C5b67 con la membrana celular del huésped haciendo a la bacteria resistente a la lisis mediada por el complemento; la endopeptidasa de inmonoglobulina G (IdeS o MspA) que inhibe la activación de los neutrófilos y la formación de EROs, la Proteasa interleucina - 8 (SpyCEP C) que destruye la interleucina-8 (IL-8) quimio atrayente de neutrófilos; la esterasa secretada por estreptococo que permite el rápido crecimiento en sangre y suero humano, las proteínas de unión al hierro ferroso $(\mathrm{Fe} 2+)$, la proteína de superficie spy 1325 que confiere a las cepas bacterianas la capacidad de adherirse fuertemente a la superficie celular, 
la adenosin sintasa A (AdsA) que le permite sobrevivir dentro de los neutrófilos permitiéndole diseminarse en sangre y tejidos periféricos. Adicionalmente, como veremos más adelante poseen las toxinas pirogénicas estreptocócicas que actúan como superantígenos promoviendo la unión de las células presentadoras de antígenos a las células efectoras del sistema inmune conduciendo a su activación policlonal (16-18).

Sumado a las estructuras de la pared celular, cobran gran importancia, en la capacidad antigénica de las bacterias gram positivas, los factores de virulencia conocidos como toxinas bacterianas, las cuales se clasifican en tres tipos de acuerdo a su modo de acción: Toxinas Tipo I, aquellas que rompen las células sin necesidad de penetrar a la célula, estás incluyen los llamados superantígenos
(SAgs) producidos por las bacterias gram positivas Staphylococcus aureus y Streptococcus pyogenes, las Tipo II que incluyen las hemolisinas y las fosfolipasas que destruyen las membranas celulares del huésped, interrumpiendo las defensas del huésped e invadiendo las células; y las toxinas Tipo III, llamadas tipo A/B, por su estructura binaria que les permite unirse a la superficie celular y tener actividad enzimática que daña la célula, interrumpen las defensas del huésped y se diseminan en los órganos cercanos (2).

Un grupo de proteínas que ha cobrado importancia es el de las llamadas superantígenos, que son exoproteínas de bajo peso molecular no glicosiladas, resistentes al calor, a la proteólisis, a los ácidos y aún a la desecación como ocurre con la toxina de síndrome de shock tóxico

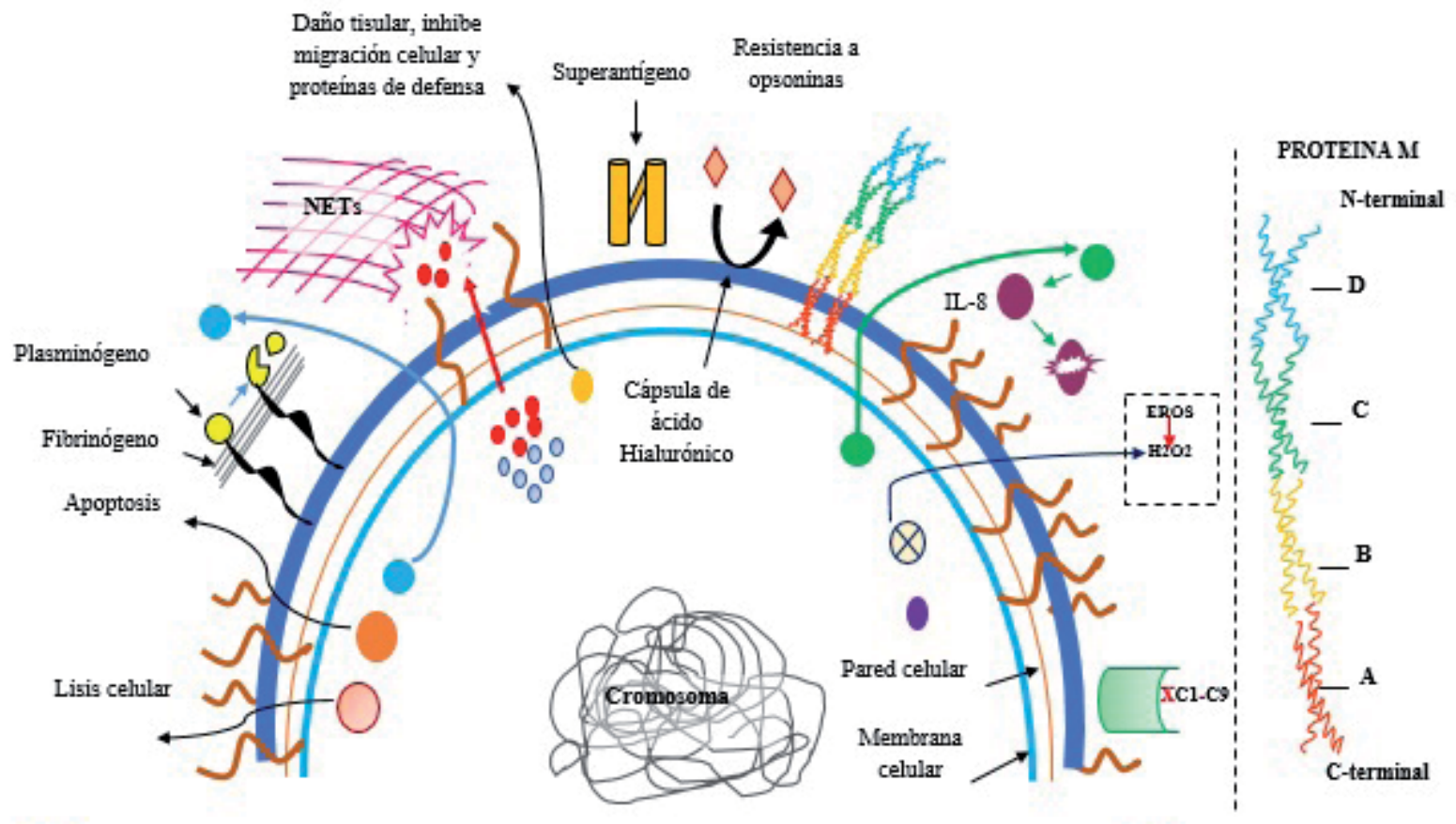

Estreptolisina O (SLO): facilita apoptosis, destrucción celular, destrucción de glóbulos rojos y células inmunes, 0 Estreptolisina 5 (SLS): facilita lisis celular Estreptocinasa: convierte plasminógeno a plasmina, Proteinasas (Ej.:- Proteasa de IL-8, Proteinasa de cisteína que destruye tejido e inhibe migración de células inmunes ), Esterasas, — Inhibidor del complemento (5ıC), 今 Pilis, Estreptodornasa extracelular: destruye NETs, 0 DNAasas: destruye los NET basados en DNA, Proteína de unión al fibrinógeno, > Proteína M: $Q$ superóxido dismutasa: convierte radicales de oxígeno a peróxido de hidrógeno.

FIGURA 2. Estructura antigénica del Streptococcus pyogenes del grupo A.

Fuente: Construida por los autores con base en las halladas en los artículos: Hynes W, Sloan M. Secreted Extracellular Virulence Factors. En: Ferretti JJ, Stevens DL, Fischetti VA. Streptococcus pyogenes: Basic Biology to Clinical Manifestations [internet]. Oklahoma: University of Oklahoma Health Sciences Center; 2016 [Consultado 2016 febrero 22]. Disponible en: https://www.ncbi.nlm.nih.gov/books/NBK333411/; y 16. Cole JN, Barnett TC, Nizet V, Walker MJ. Molecular insight into invasive group A streptococcal disease. Nat Rev Microbiol. 2011;9(10):724-36. 
1(TSST-1). Este grupo de proteínas es producido especialmente por el género Streptococcus $s p$ incluyendo el S. pyogenes, S. dysgalactiae o Streptococcus del grupo C y S. equi o Streptococcus del grupo G, además se encuentran en Staphylococcus aureus y estafilococos coagulasa negativa. Estas moléculas se consideran los más potentes activadores del sistema inmune, y de acuerdo a su secuencia de aminoácidos se pueden agrupar en tres subfamilias: la primera con secuencias homólogas en un 53 a $81 \%$ la integran los superantígenos pertenecientes a las enterotoxinas estafilocócicas (SEs) del serotipo A (SEA), D (SED), E (SEE), H (SEH) e I (SEI); la segunda se compone de la SEs del serotipo P (SEP), los des serotipo C (SECs) y la del serotipo G (SEG) que son homólogos entre sí en un 50 a $66 \%$, y finalmente la tercera familia en la que se encuentra la TSST-1 que comparte solo un $28 \%$ con el resto de los superantígenos y tiene una secuencia distintiva de 194 aminoácidos sin cisteínas ni puentes disulfuros, característicos de los demás. Todas estas moléculas son capaces de interactuar de manera simultánea con receptores de las células T (TCRs), con el complejo mayor de histocompatibilidad clase II (MHC II) de las células presentadoras de antígenos (APCs), sin que haya limitación para su unión asociada a determinantes estructurales polimórficos, adicionalmente dado que se unen a la región variable de la cadena V $\beta$ del TCR dan lugar a una respuesta inmune celular masiva dada por alta proliferación de células $\mathrm{T}$, cerca del $25 \%$ de las células $\mathrm{T}$ del individuo se activan en contraste con solo el 105-106 de células $\mathrm{T}$ que se activan con un antígeno normal dando lugar a una tormenta de citocinas poniendo en riesgo la vida del paciente; además, se da la activación de APCs como los macrófagos que finalmente junto a otros mediadores puede dar lugar al schock tóxico $(2,19-21)$.

Los estreptococos del grupo A, secretan cerca de 11, el S.pyogenes produce entre otras la exotoxina pirogénica $\mathrm{A}$, C (SPEA y SPEC), G a la M; la exotoxina mitogénica estreptocócica Z $\left(\mathrm{SMEZ}_{\mathrm{n}}\right)$ y el superantígeno estreptocócico (SSA). El Staphylococcus aureus es capaz de secretar entre 23 a 24 superantígenos diferentes serológicamente dentro de los que se encuentran más de 20 enterotoxinas estafilococcicas (SEs del inglés) entre estas la TSST-1, las SEs con serotipos $\mathrm{A}, \mathrm{B}_{\mathrm{n}}, \mathrm{C}_{\mathrm{n}},(\mathrm{N}=$ múltiples variantes $) \mathrm{D}, \mathrm{E}$, F y G; y la SE - 1 (serotipo H, I y J a la X). En función de muchos de estos superantígenos, especialmente el SEA, y con menos frecuencia el SEG, SEC, SEI, se ha explicado la patogénesis de los S.aureus y su evolución hacia la sepsis; así como la patogénesis de los S.aureus meticilina resistentes (MRSA en inglés) asociados a sepsis letal, endocarditis infecciosa y lesión renal en modelos animales debido específicamente a sus superantígenos SEA y SEC, así como al gen mecA que codifica la proteína de unión a la penicilina alterada (PBP2a) que es su principal mecanismo de resistencia a la meticilina lo que les hace unos de los microorganismos que más centran la atención en los últimos años de la comunidad científica y médica al ser responsables del aumento de la tasas de morbilidad y mortalidad de infecciones por estafilococos a nivel hospitalario y comunitario dada la multirresistencia que exhiben y el estar asociados (19-27).

Las cepas de S.aureus logran su adherencia a las células del huésped a través del grupo de proteínas conocidas como componentes de las superficie microbiana reconocidas como moléculas de adhesión a la matriz (MSCRAMMs del inglés) y además de los superantígenos mencionados, cuentan con el Sistema de dos componentes para expresión de exoproteinas de S.aureus (SaeRS TCS), operón que codifica para más de 20 factores de virulencia incluyendo hemolisinas, leucocidinas, superantígenos, proteínas de superficies y proteasas. Dentro de estos factores destacan dos grupos de proteínas que les permiten evadir la opsonofagocitosis, el primer grupo es el de las llamadas Proteínas de estafilococos inhibidoras de quimiotaxis (CHIPS) y el segundo es el de los Inhibidores del complemento de estafilococos (SCIN). CHIPS se une a los receptores celulares para $\mathrm{C} 5$ a disminuyendo la habilidad de los péptidos bacterianos para activar el complemento y actuar como quimioatrayentes de los leucocitos y SCIN inhibe la actividad de $\mathrm{C} 3$ como convertasa reduciendo el depósito de B3b opsonina sobre S.aureus y al hacerlo reduce la muerte mediado por neutrófilos. Estos dos grupos protéicos actúan en la fase temprana del crecimiento bacteriano brindando una evasión rápida de la inmunidad innata. S.aureus presenta además la coagulasa factor de virulencia estafilococcico (Coa) y la proteína de unión al factor de Willebrand, ambos promueven la activación no catalítica de la protrombina favoreciendo la ruptura de las cadenas $\mathrm{A} \alpha$ y $\mathrm{B} \beta$ del fibrinógeno soluble y con esto la formación de coágulos de fibrina que promoverán los factores de aglutinación mediados por proteínas (ClfA y ClfB) para agregación de estafilococos, los cuales permitirán la aglutinación de S.aureus en la sangre asegurando su supervivencia al protegerlo de la fagocitosis y contribuyendo además, al manipular la coagulación del huésped, a la respuesta inflamatoria sistémica $(5,19,28,29)$. 
A nivel sanguíneo, las células inmunes circulantes y el endotelio vascular son los blancos primarios de los factores de virulencia de los estafilococos quienes sumado a todo lo anterior, producen una serie de leucotoxinas, moléculas compuestas por dos componentes protéicos "S" y "F", que se ensamblan sobre la superficie celular formando poros tipo $\beta$-barril en la superficie celular de los leucocitos incluyendo los neutrófilos, fagocitos mononucleares y células $\mathrm{T}$, en quienes alteran la regulación osmótica, favoreciendo la entrada de calcio, activando genes de transcripción de citocinas proinflamatorias como IL-8, Leucotrieno 4; activando el inflamosoma por unión con el receptor intracelular NLRP3 que desencadena la vía de la caspasa 1 y la activación de citocinas infalmatorias como la IL-1 $\beta$, IL-18 e IL-33; secuestrando el hierro necesario para el crecimiento bacteriano y conduciendo finalmente a la lisis celular. En las cepas de S.aureus y en muchas de las MRSA, asociadas a infecciones humanas se encuentran 5 leucotoxinas, entre las cuales se sabe que existe antagonismo y sinergismo bloqueándose o potenciándose entre ellas, respectivamente, llevando a que la virulencia y patogénesis del microorganismo cambie. Estas son: Leucocidina Panton - Valentin (PVL), Leucocidina AB/ GH (LukAB/GH), Leucocidina ED (LukED) y gamma $(\gamma)$ hemolisina (HlgABC) en sus dos formas: $\mathrm{HlgAB}$ o como $\mathrm{HlgCB}$; esta última además lisa eficientemente los glóbulos rojos promoviendo la supervivencia del S. aureus en sangre; y péptidos citolíticos llamados modulinas solubles fenólicas (PSMs). La expresión icrementada de estos dos grupos de moléculas de virulencia, se encuentran en las cepas de S.aureus meticilino resistentes, en los que se han descrito como uno de sus mecanismos moleculares que incrementan la severidad de la enfermedad asociada a estas cepas (5,29-32).

\section{Identificación antigénica e Inicio de respuesta}

Dado que en el caso de las bacterias gram positivas encontramos tanto los PAMPs que son el PNG y el LTA que activan el sistema de la inmunidad innata, y al mismo tiempo los superantígenos que como veremos estimulan principalmente las células $\mathrm{T}$ y la inmunidad adaptativa, al exponerse el paciente de manera simultánea a ambos grupos de moléculas antigénicas se desencadena una activación sinérgica de ambos sistemas de la inmunidad que ayuda a explicar las condiciones clínicas y el empeoramiento del paciente en patologías como la sepsis y otras como el síndrome de shock tóxico y la neumonía (33).
El proceso de identificación antigénica, en el caso de los superantígenos, de manera convencional inicia por la unión de estos como moléculas intactas, a la cara externa de superficie celular a través del complejo mayor de histocompatibilidad clase II (CMH II) expresado sobre las células presentadoras de antígenos. Posteriormente por la unión una zona específica de la región variable de la cadena $\beta$ del receptor de la célula T (TCR V $\beta$ ); a diferencia de los antígenos normales que se unen a la región $\alpha \beta$ del receptor T; presente tanto en células CD4 como CD8, llegando a activar entre el $30 \%$ al $70 \%$ del pool total de las células T. Se sabe también que los superantígenos son capaces de unirse al receptor CD28, un co-estimulador molecular sobre las células $T$. Una vez activadas las células $\mathrm{T}$, por ambas vías, cada una inicia su función incluyendo la secreción de gran cantidad de citocinas proinflamatorias, dando lugar a la llamada "tormenta de citocinas"; la liberación de factores tisulares, enzimas líticas, especies reactivas de oxígeno (EROs) que finalmente desencadena el síndrome de respuesta inflamatoria sistémica, hipotensión, falla multiorgánica e incluso muerte. En paralelo a esto, la respuesta inducida por los superantígenos parece afectar las células de la inmunidad adaptativa al impedir que desencadenen respuestas específicas contra el S. aureus $(2,33-35)$.

Una vez se unen los superantígenos a al CMH II y al TCR V $\beta$, se activan la señalización intracelular por diferentes vías: la vía del fosfatidil inositol, la protein cinasa $\mathrm{C}$ (PKC) y la proteína tirosina cinasa Lck asociada con los co - receptores CD4 y CD8 y adicionalmente en caso de no proceder la señalización por la Lck, se da por la vía alterna de la fosfolipasa $C \beta$ asociada a proteína $G(\mathrm{G} \alpha 11$ / PLC $\beta$ ). La activación de estas vías conduce a la activación de los factores de transcripción $\mathrm{NK}-\kappa \mathrm{B}$ y AP -1 que lleva a la expresión de la citocinas proinflamatorias y moléculas de adhesión en macrófagos y células T. Los superantígenos activan igualmente las células presentadoras de antígenos contribuyendo a la liberación de citocinas mediante la activación de la vía del factor de diferenciación mieloide (MyD88) que regula el $\mathrm{NK}-\kappa \mathrm{B}$ que lleva a la trascripción de los genes que codifican las citocinas proinflamatorias (Figura 3) $(20,36)$.

En el caso del PGN y el LTA, son reconocidos como PAMPs de forma similar a como es reconocida la endotoxina de las gram negativas, pero a diferencia de las gram negativas, la señalización inducida tras la activación 
de la inmunidad innata por las gram positivas es mucho más baja que la inducida por las gram negativas, y aún se continúa investigando respecto a la especificidad de los PAMPs de las gram positivas y los mecanismos que permiten su reconocimiento. Los componentes lipoproteicos del ácido lipoteicoico son reconocidos por receptores de reconocimiento de patrones (PRRs) del tipo Toll (TLRs) que pertenecen a las glicoproteínas transmembrana que contienen dominios extracelulares repetidos ricos en leucina (LRR) que reconocen el ligando, en este caso el PAMP, y un dominio intracelular de señalización llama- do receptor Toll/Interleucina - 1 (TIR). Para el reconocimiento del PAMP de las gram positivas, el LTA, participa el receptor TLR2 que puede reconocer glicolípidos como los hallados en el ácido lipoteicoico, sin embargo, para poder reconocer el PAMP de las gram positivas se forman heterodímeros con el receptor TLR6, y moléculas de superficie como el CD14 y el CD36 que se hallan en las células del sistema de defensa del cuerpo como los macrófagos y se les ha llamado co-receptores. Hoy en día se sabe que el tipo de amino ácidos de la cadena peptídica, el el número de residuos acilo de las lipoproteínas (grado de

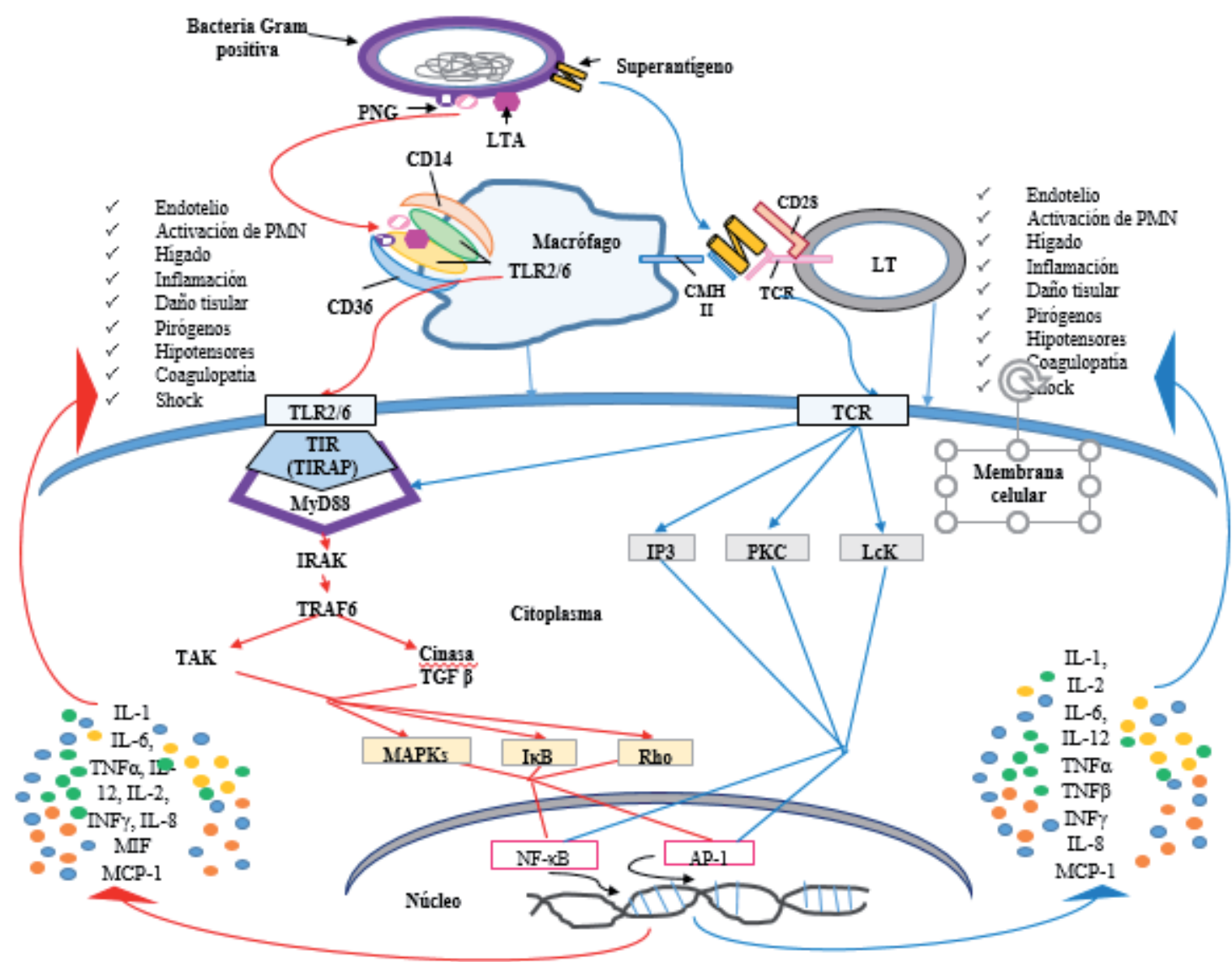

FIGURA 3. Identificación antigénica e inicio de respuesta inflamatoria inducida por los superantígenos, el PGN y el LTA de bacterias gram positivas. Fuente: Construida por los autores con base en las halladas en: 20. Krakauer T. Therapeutic down-modulators of staphylococcal superantigeninduced inflammation and toxic shock. Toxins (Basel). 2010;2(8):1963-83.; Schmidt RR, Pedersen CM, Qiao Y, Zähringer U. Chemical synthesis of bacterial lipoteichoic acids: an insight on its biological significance. Org Biomol Chem. 2011;9(7):2040-52. 
acilación) son determinantes para que sean reconocidas por los TLRs, así las moléculas diaciladas, presentes en el LTA, son reconocidas por el complejo TLR2/6 y se unen específicamente a los LRR, activando los dominicos intracelulares TIR y dando inicio a la cascada de señalización que lleva finalmente a la producción de citocinas, la respuesta inflamatoria y el proceso de sepsis. En línea con anterior se sabe además que el número de residuos de D-alanina es uno de los factores determinantes de la potencia de la respuesta inflamatoria desencadenada por las bacterias gram positivas, así el LTA de S.aureus tiene $70 \%$ de residuos de D-alanina, frente a solo $25 \%$ en $\mathrm{B}$. subtillis, siendo más potente inductor de la respuesta inflamatoria el S. aureus (Figura 3) (6,37-39).

El inicio de la cascada de señalización intracelular se da a través de moléculas intracelulares que se adaptan a los dominios TIR del receptor TLR2/6, dentro de estas se encuentran el factor de diferenciación mieloide (MyD88) y la proteína adaptadora con dominio TIR (Mal o TIRAP). La TIRAP recluta la MyD88 y esta vía activa las proteínas cinasas asociadas al receptor de IL-1 (IRAK) y del factor 6 asociado al TNF (TRAF-6) que una vez activadas, conducen a la activación de mediadores como la cinasa activadora del factor de crecimiento transformante (TAK) y la cinasa activadora del factor de crecimiento transformante $\beta$, que a la vez activaran tres vías de señalización intracelular en las que participan: 1) las proteínas cinasas activadoras de mitógenos (MAPKs) del tipo p42/ $\mathrm{p} 44$, JNK1/2, p38, 2) las cinasas IкB y 3) pequeñas GTPasas de la familia Rho. Las tres vías activaran, mediante la participación de otras moléculas de señalización intermedia que aún están en estudio, los factores de transcripción como factor nuclear kappa B (NF-kB) y AP-1 que regularán la expresión de los genes que codifican las citocinas y quimiocinas que desencadenaran diversas respuestas a nivel sistémico durante la sepsis, dentro de estas la IL-1, IL-6, TNF $\alpha$, IL-12, IL-2, INF $\gamma$, IL-8, el factor inhibidor de la migración de macrófagos (MIF), la proteína quimiotrayente de monocitos-1 (MCP-1), entre otras. Adicionalmente tanto la MAPKs p38 como la familia Rho lleva a modificaciones del citoesqueleto, pérdida de uniones adherentes y diminución de los gap intercelular en las células endoteliales infectadas por S.aureus en quienes fue reconocido el LTA o el PNG, alterando esta barrera y la permeabilidad a nivel vascular $(6,20,40,41)$.

\section{Mediadores Químicos y disfunción sistémica: La fisiopatología explicando la clínica}

Las bacterias gram positivas son los agentes etiológicos de una de las manifestaciones más extremas de la sepsis, el llamado shock séptico, en el que la lesión vascular y la inflamación sistémica llevan a compromiso de la función cardiaca y la presión sanguínea con el daño final del aporte de oxígeno en los tejidos y falla orgánica. La explicación molecular de estas manifestaciones clínicas se encuentra al comprender el curso que siguen las diferentes moléculas generadas durante el reconocimiento y la activación de la respuesta inmune ante, en este caso, las bacterias gram positivas (Figura 3, Tabla 1).

Tanto los gram positivos como los gram negativos inducen la activación de los elementos del sistema inmune, como hemos visto, sin embargo, las gram positivas parecen activar de forma más prominente los neutrófilos y los linfocitos $\mathrm{T}$ y respecto a la concentración de las citocinas liberadas bajo el estímulo de uno u otro tipo de bacterias, se ha encontrado que aunque ambos grupos de bacterias inducen un mismo perfil de citocinas liberadas en la respuesta inmune inducida, la concentración de las mismas es diferente según se trate de una infección por bacterias gram negativas o gram positivas. Aunque en estudios in vitro se halla que la concentración de citocinas es mayor en el caso de las primeras, in vivo, la toxicidad inflamatoria de las bacterias gram positivas es innegable y se explica dada la acción sinérgica antigénica que exhibe el LTA junto al PNG, específicamente junto a los dipéptidos murámicos del $\mathrm{PNG}$ que son reconocidos por los receptores NOD intracelulares y desencadenan vías de señalización intracelular que activarán la liberación de citocinas pro inflamatorias. La diferencia en la cantidad de citocinas inflamatorias inducidas por uno u otro tipo de bacterias, ha llevado a que en diversos estudios se haya encontrado que la medición rápida de éstas se plantee como un indicador que puede ayudar a discriminar si la bacteremia del paciente es por gram positivas o por gram negativas, así se ha encontrado en algunos estudios que en el caso de la sepsis por bacterias gram negativas se detectan mayores niveles de TNF $\alpha$-, IL- $1 \alpha$, IL-1 $\beta$, e IL- 8 , y en sepsis por gram positivas el TNF $\alpha$, IL- $1 \beta$ TNF $\beta$, IL-4 $\alpha$, IL-18; en otros estudios se enfatiza que las mayores diferencias se observan a nivel de TNF $\alpha$, Il-6, e IL-10, siendo la IL-10 
un potencial marcador de la bacteremia por gram negativos en pacientes pediátricos hematológicos u oncológicos. Igualmente se ha encontrado que frente al efecto sobre la producción de marcadores de sepsis como es la procalcitonina (PCT en inglés), resulta más efectivo el Lipopolisacárido de las bacterias gram negativas de ahí que la PCT se esté considerando como un agente predictor de la etiopatogenia de la sepsis (42-46).

Uno de los primeros fenómenos que ocurre en la infección por bacterias gram positivas, gracias a la participación de las proteínas de anclaje de la pared celular (CWA) dentro de las que se encuentran la las proteínas de unión a la fibronectina (FnBPs tipo A y B), que además participan en la formación de biopelículas sobre superficies inertes como catéteres e invasión de células epiteliales, endoteliales, fibroblastos, osteoblastos y queratinocitos por parte de bacterias como el S.aureus y específicamente de endotelio vascular por parte de las cepas de S.aureus meticilino resistentes (MRSA); es su adherencia al endotelio generando cambios en el microambiente de los pequeños vasos o lo de flujo lento como los sinusoides hepáticos en los que con ayuda de las ClfA y ClfB inducirán la coagulación y formación de agregados que le permitirá evadir el sistema inmune por mecanismos como al evasión de la fagocitosis por neutrófilos al unirse el ClfA al factor 1 del complemento. Luego de la adhesión, otro mecanismo molecular involucrado en la fisipatología de la infección por estos microorganismos, es el aumento de la permeabilidad vascular inducida por las bacterias lo cual se da por la disrupción endotelial ante la inflamación extrema y por acción de las toxinas bacterianas como la $\alpha$ toxina que rompe las uniones intercelulares a nivel de las uniones de cadherina en las células endoteliales. Esta pérdida de integridad de la barrera endotelial promueve la diseminación bacteriana lo cual es determinante en la fisiopatología de la sepsis $(5,47)$.

Una vez se activa la respuesta inmune ante la infección por bacterias gram positivas, las citocinas inflamatorias liberadas, ejercerán sus funciones a través de receptores y vías de señalización específicas. Así la IL-1 interactúa con su receptor (IL-1R1) y activa la cascada de señalización de la MyD88, las IRAK y el TRAF-6; el TNF $\alpha$ se une a sus receptores (TNFR) y usa TRAF diferentes a los de la IL-1, pero que finalmente activan el NF-אB que llevará a la expresión de otras citocinas y moléculas coestimuladoras. Además, el receptor del TNF $\alpha$ posee dominios que inducen muerte celular mediante la activación de las cas- pasas. El INF $\gamma$ se une a su receptor IFN $\gamma \mathrm{R}$ y sinergiza la actividad de IL-1 y TNF $\alpha$. Luego de activadas las vías de señalización, cada una de esta citocinas desencadenaran respuestas manifestadas en la clínica del paciente como son la fiebre, la hipotensión, taquicardia, compromiso cardiovascular, alteraciones microvasculares, coagulopatía, lesión pulmonar, entre otras (Tabla 1) $(20,41)$.

Las quimiocinas liberadas desde las células activadas por lo superantígenos de las bacterias gram positivas, atraen neutrófilos, células $\mathrm{T}$, células dendríticas, monocitos y otro tipo de células que a través de receptores acoplados a proteínas $\mathrm{G}$ inducen la entrada de calcio y la activación de la fosfolipasa $C \beta$. Los neutrófilos activados migran a los sitios de lesión tisular e inflamación donde producen especies reactivas de oxígeno y proteasas que favorecen el daño celular y tisular; producen óxido nítrico que actuar como vasodilatador contribuye a la hipotensión característica del shock séptico. Por su parte las citocinas liberadas durante la respuesta inflamatoria inducida por los superantígenos de los gram positivos, específicamente $S$. aureus y $S$. pyogenes, cuya acción permite entender las manifestaciones clínicas de la sepsis, se encuentran: el TNF $\alpha$, TNF $\beta$ y la IL-1 que en asocio a otras citocinas actúan como pirógenos e hipotensores, inducen metabolitos del ácido araquidónico, factor activador plaquetario (PAF); el INF $\gamma$, citosina promotora de Linfocitos T helper tipo 1 (LTh 1) actúa en sinergia con los dos anteriores para promover la reacción inmune y lesión tisular, además produce rash cutáneo. Tanto el TNF $\alpha$ como la IL-1 y la IL-6, actúan en el hígado liberando reactantes de fase aguda, activan vías apoptóticas y disminuyen la función de limpieza del hígado. la Interleucina 2 (IL-2) genera vasodilatación que contribuye a la extravasación vascular y el edema; la interleucina 8 (IL-8), la proteína - 1 quimiotrayente de monocitos (MCP-1), que activan y dirigen la migración de leucocitos, neutrófilos y células dendríticas hacia el tejido lesionado. Todos estos mediadores en alta concentración inducen disfunción orgánica y muerte (Tabla 1) $(20,40)$.

Uno de los procesos que caracteriza las manifestaciones clínicas de la sepsis es la coagulopatía cuya magnitud puede variar desde un nivel insignificante hasta llegar a la coagulación intravascular diseminada (CID) caracterizada por activación sistémica de la coagulación, disminución de plaquetas, formación intravascular de fibrina, consumo de los factores de coagulación dando lugar a trombos que obstruirán la irrigación sanguínea condu- 
ciendo a disfunción orgánica. Muchas de las moléculas liberadas tras el reconocimiento de los PAMPs provenientes de las bacterias gram positivas, como son el TNF $\alpha$ y la IL-1 activan el factor de transcripción NF- $\mathrm{B}$ en diversos tipos de células incluyendo las células epiteliales y endoteliales, y estas dos citocinas de manera sinérgica con el INF- $\gamma$ incrementa la expresión de CMH-II, moléculas de adhesión y factor tisular sobre las células endoteliales, la expresión incrementada de este último no solo en las células endoteliales sino en células mononucleares, conduce a la activación del sistema de coagulación resultando en la CID que a la vez magnifica la respuesta inflamatoria al promover por medio de la trombina la producción de citocinas como TNF $\alpha$, la IL-1 e IL-6. El TNF $\alpha$ y la IL-1 adi- cionalmente estimulan la actividad fibrinolítica al inducir la liberación del activador tisular del plasminógeno (TPA) que activa el plasminógeno y degrada la fibrina; y de forma paralela aumentan la actividad fibrinolítica activando el inhibidor del activador del plasminógeno tipo 1 (PAI-1) y el factor inhibidor activable de trombina (TAFI) presentes en la falla multiorgánica de la sepsis. La vía de la coagulación a través del factor XIIa puede activar el componente $\mathrm{C} 1$ del complemento, y la CID puede igualmente activar el componente C5a del mismo, a la vez el sistema del complemento amplifica la coagulación modificando los fosfolípidos de las membranas, activando plaquetas e induciendo la expresión del factor tisular (Tabla 1) (48).

TABLA 1. Moléculas liberadas durante la respuesta inflamatoria ante bacterias gram positivas y algunos de sus efectos expresados en la clínica del paciente con sepsis.

Manifestación Clínica

Fiebre

\begin{tabular}{|c|c|c|}
\hline $\begin{array}{l}\text { Shock distributivo y } \\
\text { posteriormente car- } \\
\text { diogénico }\end{array}$ & $\begin{array}{l}\text { Mediadores celu- } \\
\text { lares y las toxinas } \\
\text { bacterianas }\end{array}$ & $\begin{array}{l}\text { Causan shock circulatorio distributivo: hipotensión, taquicardia, } \\
\text { disminución de resistencia vascular sistémica y aumento de gasto } \\
\text { cardiaco; posteriormente hay disfunción sistólica y diastólica }\end{array}$ \\
\hline & TNF $\alpha$, IL-1. IL-6 & Actúan directamente sobre miocardio como depresores \\
\hline & $\begin{array}{l}\text { Óxido nítrico }(\mathrm{NO}) \text { y } \\
\text { los productos genera- } \\
\text { dos por la ciclooxi- } \\
\text { genasa }\end{array}$ & $\begin{array}{l}\text { Depresoras de miocardio. ElNO incrementa la relajación miocárdica, } \\
\text { el aumento de volumen final de diástole y aumento de presión final } \\
\text { de diástole del Ventrículo Izquierdo; es antagonista de los beta adre- } \\
\text { nérgicos, induce menor respuesta del miocito al calcio intracelular, }\end{array}$ \\
\hline & Citocinas & $\begin{array}{l}\text { Reducen el calcio intracelular en el miocito afectando la contracción } \\
\text { miocárdica. }\end{array}$ \\
\hline \multirow[t]{3}{*}{$\begin{array}{l}\text { Disfunción } \\
\text { microvascular }\end{array}$} & Óxido Nítrico (NO) & $\begin{array}{l}\text { Por medio dela vía del } 3 \text { ` } 5 \text { guanosinmonofosfato cíclico (GMPc) } \\
\text { causa vasodilatación e hipotensión arterial sistémica, haciendo que } \\
\text { domine en la sepsis el tono vasodilatador alterando la capacidad } \\
\text { de la microcirculación para asegurar la oxigenación tisular; Es } \\
\text { responsable de caída en resistencia vascular sistémica y con esto el } \\
\text { desarrollo de hipotensión. }\end{array}$ \\
\hline & IL-2 & Vasodilatación \\
\hline & $\begin{array}{l}\text { Por acúmulo de leucoc } \\
\text { radicales libres de } \mathrm{O} 2 \text {. }\end{array}$ & s y plaquetas en los capilares, se da fuga de líquidos, producción de \\
\hline
\end{tabular}




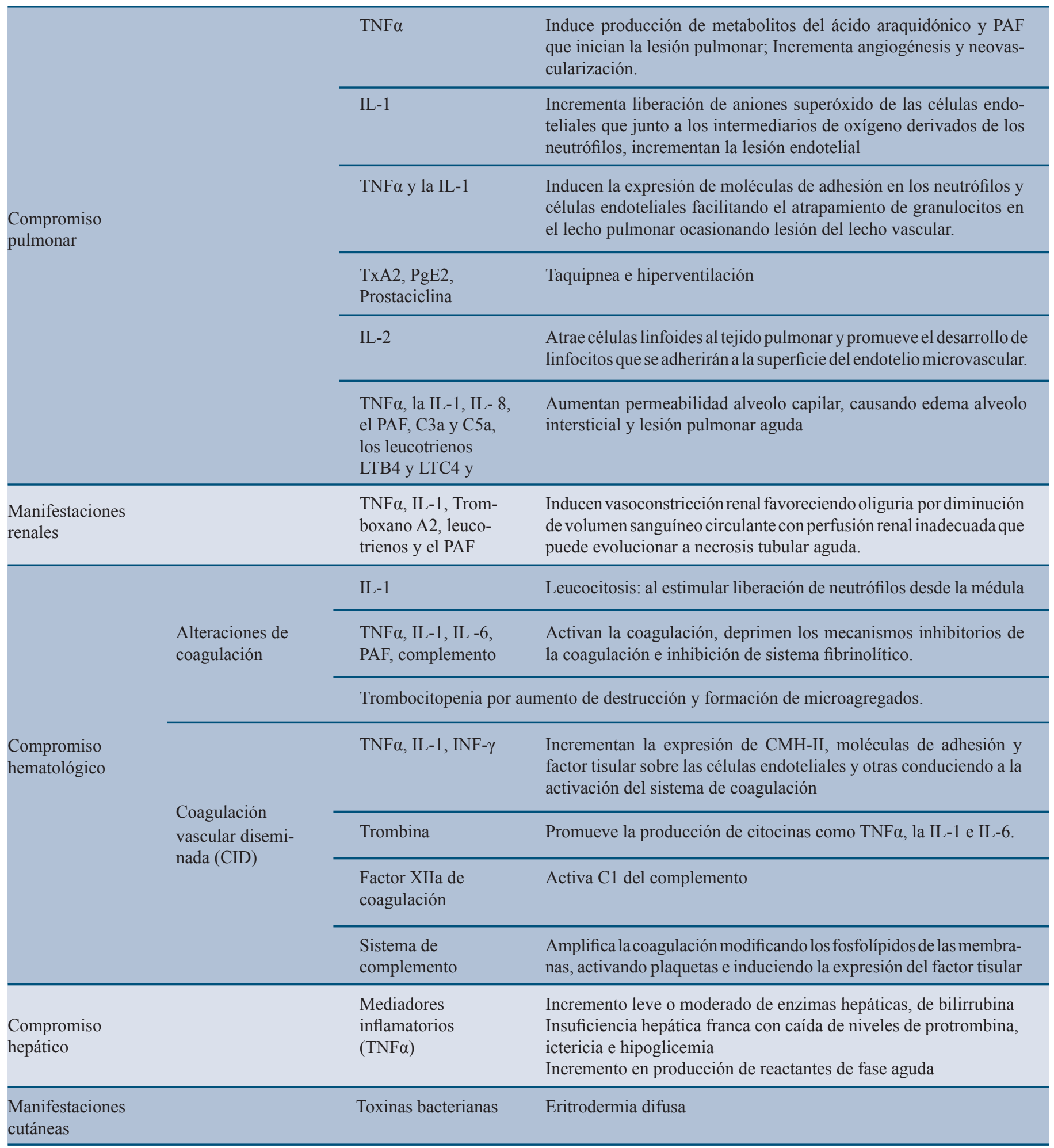

Elaborada por los autores a partir de: Zapata JP. Sepsis: la otra cara de la respuesta inmune. Iatreia.2011;24(2):179-190; 25; Wu T, Xing J, Birukova AA Cell-type-specific crosstalk between p38 MAPK and Rho signaling in lung micro- and macrovascular barrier dysfunction induced by Staphylococcus aureus-derived pathogens. Transl Res. 2013;162(1):45-55; Carrillo R.C, Tapia J, Peña C.A, Kim Kohd M.J, Jaime A.R, Montalvo E. Bases moleculares de la sepsis. Revista de la Facultad de Medicina de la UNAM. 2014;57(3):1-13; Briceño I. Sepsis: Etiología, Manifestaciones Clínicas y Diagnóstico. Medicrit 2005; 2(9):203-213; Latini R, Caironi P, Masson S. Cardiac dysfunction and circulating cardiac markers during sepsis. Minerva Anestesiol. 2016;82(6):697-710. 
Se ha encontrado que la magnitud de la respuesta inflamatoria y el desenlace del síndrome de shock tóxico causado por bacterias grampositivas, se relaciona con haplotipos específicos del CMH II, aquellos pacientes que presentan el haplotipo DR15/DQ6 del complejo mayor de histocompatibilidad II, tienen una proliferación reducida de células $\mathrm{T}$ en respuesta a los superantígenos de los estreptococos, parece ser un factor protector ante el desarrollo de infecciones severas por estos microorganismos, exhiben un mayor nivel de citocinas anti - inflamatorias como la IL - $10(40,49)$.

\section{Conclusión}

En la fisiopatología de la sepsis, conocer cuál es el agente causal de la misma, permite comprender los mecanismos moleculares que desencadenan todos y cada una de las manifestaciones clínicas que presentan los pacientes. En el caso de las bacterias gram positivas la existencia de diversos mecanismos de virulencia incluidos el PGN, el LTA, los superantígenos, las leucotoxinas, las coagulasas entre otros, hacen de este grupo de microorganismos capaces de evadir el sistema inmune innato del huésped y avanzar en el desencadenamiento de respuesta inmunes masivas y simultáneas en las que cada una de las moléculas proinflamatorias liberadas llevan a la instauración de procesos sépticos en el paciente. El conocer los mecanismos por los que estas moléculas desencadenan los procesos orgánicos y sistémicos de la sepsis se convierten en el blanco terapéutico para el médico y el potencial sobre el cual se puede avanzar en el desarrollo de nuevas opciones de manejo y prevención de complicaciones de esta patología.

\section{Referencias}

1. Martin GS. Sepsis, severe sepsis and septic shock: changes in incidence, pathogens and outcomes. Expert Rev Anti Infect Ther. 2012;10(6):701-6.

2. Ramachandran G. Gram-positive and gram-negative bacterial toxins in sepsis: a brief review. Virulence. 2014;5(1):213-8.

3. Silveira-Lessa AL, Quinello C, Lima L, Redondo AC, Ceccon ME, Carneiro-Sampaio M, et al. TLR expression, phagocytosis and oxidative burst in healthy and septic newborns in response to Gram-negative and Gram-positive rods. Hum Immunol. 2016:S0198-8859(16)30383-4:1-9.

4. Reglinski M, Sriskandan S. The contribution of group A streptococcal virulence determinants to the pathogenesis of sepsis. Virulence. 2014;5(1):127-36.
5. Powers ME1, Bubeck Wardenburg J. Igniting the fire: Staphylococcus aureus virulence factors in the pathogenesis of sepsis. PLoS Pathog. 2014;10(2):1-1.

6. Kang SS, Sim JR, Yun CH, Han SH. Lipoteichoic acids as a major virulence factor causing inflammatory responses via Toll-like receptor 2. Arch Pharm Res [internet]. 2016:1-11 [consultado 2016 Agosto 20]. DOI:10.1007/s12272-016-0804-y

7. Henneke P1, Dramsi S, Mancuso G, Chraibi K, Pellegrini E, Theilacker C, et al. Lipoproteins are critical TLR2 activating toxins in group B streptococcal sepsis. J Immunol. 2008;180(9):6149-58.

8. Bern M, Beniston R, Mesnage S. Towards an automated analysis of bacterial peptidoglycan structure. Anal Bioanal Chem [internet]. 2016:1-10 [consulado 2016 Agosto 20]. DOI 10.1007/ s00216-016-9857-5

9. Malanovic N, Lohner K. Gram-positive bacterial cell envelopes: The impact on the activity of antimicrobial peptides. Biochim Biophys Acta. 2016;1858(5):936-46.

10. Gupta VK, Sekhar S, Dhanda V, Toor D, Kumar R, Chakraborti A. Immune response against $\mathrm{M}$ protein-conserved region peptides from prevalent group A Streptococcus in a North Indian population. J Microbiol Immunol Infect. 2016 ;49(3):352-8.

11. Young PG1, Moreland NJ2, Loh JM3, Bell A4, Atatoa Carr P5, Proft $\mathrm{T}$, et al. Structural conservation, variability, and immunogenicity of the T6 backbone pilin of serotype M6 Streptococcus pyogenes. Infect Immun. 2014;82(7):2949-57.

12. Hynes W, Sloan M. Secreted Extracellular Virulence Factors. En: Ferretti JJ, Stevens DL, Fischetti VA. Streptococcus pyogenes: Basic Biology to Clinical Manifestations [internet]. Oklahoma: University of Oklahoma Health Sciences Center; 2016 [Consultado 2016 febrero 22]. Disponible en: https://www.ncbi.nlm.nih. gov/books/NBK333411/

13. Immacuada Margarit y Ros. Streptococcus pyogenes Pili. En: Ferretti JJ, Stevens DL, Fischetti VA. Streptococcus pyogenes: Basic Biology to Clinical Manifestations [internet]. Oklahoma: University of Oklahoma Health Sciences Center; 2016 [Consultado 2016 febrero 22]. Disponible en: https://www.ncbi.nlm.nih. gov/books/NBK333423/

14. Ryan PA, Juncosa B. Group A Streptococcal Adherence. En: Ferretti JJ, Stevens DL, Fischetti VA. Streptococcus pyogenes: Basic Biology to Clinical Manifestations [internet]. Oklahoma: University of Oklahoma Health Sciences Center; 2016 [Consultado 2016 febrero 22]. Disponible en: https://www.ncbi.nlm.nih.gov/ books/NBK333427/

15. Fischetti VA. M Protein and Other Surface Proteins on Streptococci. En: Ferretti JJ, Stevens DL, Fischetti VA. Streptococcus pyogenes: Basic Biology to Clinical Manifestations [internet]. Oklahoma: University of Oklahoma Health Sciences Center; 2016 [Consultado 2016 febrero 22]. Disponible en: https://www. ncbi.nlm.nih.gov/books/NBK333431/

16. Cole JN, Barnett TC, Nizet V, Walker MJ. Molecular insight into invasive group A streptococcal disease. Nat Rev Microbiol. 2011;9(10):724-36. 
17. Golińska E, Van der Linden M, Więcek G, Mikołajczyk D, Machul A, Samet A, et al. Virulence factors of Streptococcus pyogenes strains from women in peri-labor with invasive infections. Eur J Clin Microbiol Infect Dis. 2016;35(5):747-54.

18. Kim HK, Thammavongsa V, Schneewind O, Missiakas D. Recurrent infections and immune evasion strategies of Staphylococcus aureus. Curr Opin Microbiol. 2012 Feb;15(1):92-9. doi: 10.1016/j.mib.2011.10.012. Epub 2011 Nov 14.

19. Spaulding AR, Salgado-Pabón W, Kohler PL, Horswill AR, Leung DY, Schlievert PM. Staphylococcal and streptococcal superantigen exotoxins. Clin Microbiol Rev. 2013;26(3):422-47.

20. Krakauer T. Therapeutic down-modulators of staphylococcal superantigen-induced inflammation and toxic shock. Toxins (Basel). 2010;2(8):1963-83.

21. Proft T, Fraser JD. Streptococcal Superantigens: Biological propierties and potential role in disease. En: Ferretti JJ, Stevens DL, Fischetti VA. Streptococcus pyogenes: Basic Biology to Clinical Manifestations [internet]. Oklahoma: University of Oklahoma Health Sciences Center; 2016 [Consultado 2016 febrero 22]. Disponible en: https://www.ncbi.nlm.nih.gov/books/NBK333435/

22. Aman MJ. Superantigens of a superbug: Major culprits of Staphylococcus aureus disease?. Virulence. 2016; 2:1-4.

23. Liu Q, Yeo WS, Bae T. The SaeRS Two-Component System of Staphylococcus aureus. Genes (Basel). 2016;7(10):1-20.

24. Corredor Arias LF1, Luligo Espinal JS2, Moncayo Ortiz J12, Santacruz Ibarra JJ3, Álvarez Aldana A. Relationship between super antigenicity, antimicrobial resistance and origin of Staphylococcus aureus isolated. Colomb Med (Cali). 2016;47(1):15-20.

25. Salgado-Pabón W1, Breshears L, Spaulding AR, Merriman JA, Stach CS, Horswill AR, et al. Superantigens are critical for Staphylococcus aureus Infective endocarditis, sepsis, and acute kidney injury. MBio. 2013;4(4):1-9.

26. Deodhar D, Varghese G, Balaji V, John J, Rebekah G, Janardhanan J, et al. Prevalence of Toxin Genes among the Clinical Isolates of Staphylococcus aureus and its Clinical Impact. J Glob Infect Dis. 2015;7(3):97-102. doi: 10.4103/0974-777X.162234.

27. Imani Fooladi AA, Ashrafi E, Tazandareh SG, Koosha RZ, Rad HS, Amin M, et al. The distribution of pathogenic and toxigenic genes among MRSA and MSSA clinical isolates. Microb Pathog. 2015;81:60-66.

28. McAdow M, Kim HK, Dedent AC, Hendrickx AP, Schneewind O, Missiakas DM. Preventing Staphylococcus aureus sepsis through the inhibition of its agglutination in blood. PLoS Pathog. 2011;7(10):e1002307.

29. Aslam R, Laventie BJ, Marban C, Prévost G, Keller D, Strub JM, Dorsselaer Av, Haikel Y, Taddei C, Metz-Boutigue MH. Activation of neutrophils by the two-component leukotoxin LukE/D from Staphylococcus aureus: proteomic analysis of the secretions J Proteome Res. 2013;12(8):3667-3678.

30. Yoong P, Torres VJ. The effects of Staphylococcus aureus leukotoxins on the host: cell lysis and beyond. Curr Opin Microbiol. 2013;16(1):63-69.
31. Yoong P, Torres VJ. Counter inhibition between leukotoxins attenuates Staphylococcus aureus virulence. Nat Commun. 2015;6(8125.):1-10.

32. Malachowa N, Kobayashi SD, Braughton KR, Whitney AR, Parnell MJ, Gardner DJ, Deleo FR. Staphylococcus aureus leukotoxin GH promotes inflammation. J Infect Dis. 2012;206(8):11851193.

33. Tilahun AY, Karau M, Ballard A, Gunaratna MP, Thapa A, David CS, Patel R, Rajagopalan G. The impact of Staphylococcus aureus-associated molecular patterns on staphylococcal superantigen-induced toxic shock syndrome and pneumonia. Mediators Inflamm. 2014; 2014:468285.

34. Tilahun AY, Chowdhary VR, David CS, Rajagopalan G. Systemic inflammatory response elicited by superantigen destabilizes $\mathrm{T}$ regulatory cells, rendering them ineffective during toxic shock syndrome. J Immunol. 2014;193(6):2919-30.

35. Kulhankova K, King J, Salgado-Pabón W. Staphylococcal toxic shock syndrome: superantigen-mediated enhancement of endotoxin shock and adaptive immune suppression. Immunol Res. 2014;59(1-3):182-7.

36. Xu SX, McCormick JK. Staphylococcal superantigens in colonization and disease. Front Cell Infect Microbiol. 2012;2(52):1-11.

37. Kak V. Mediators of systemic inflammatory response syndrome and the role of recombinant activated protein $\mathrm{C}$ in sepsis syndrome. Infect Dis Clin North Am. 2011;25(4):835-50.

38. Schmidt RR, Pedersen CM, Qiao Y, Zähringer U. Chemical synthesis of bacterial lipoteichoic acids: an insight on its biological significance. Org Biomol Chem. 2011;9(7):2040-52.

39. Ray A, Cot M, Puzo G, Gilleron M, Nigou J. Bacterial cell wall macroamphiphiles: pathogen-/microbe-associated molecular patterns detected by mammalian innate immune system. Biochimie. 2013;95(1):33-42.

40. Zapata JP. Sepsis: la otra cara de la respuesta inmune. Iatreia.2011;24(2):179-190.

41. Wu T, Xing J, Birukova AA Cell-type-specific crosstalk between p38 MAPK and Rho signaling in lung micro- and macrovascular barrier dysfunction induced by Staphylococcus aureus-derived pathogens. Transl Res. 2013;162(1):45-55.

42. Surbatovic M, Popovic N, Vojvodic D, Milosevic I, Acimovic G, Stojicic M, et al. Cytokine profile in severe Gram-positive and Gram-negative abdominal sepsis. Sci Rep. 2015;5(11355):1-12.

43. Xu XJ, Tang YM, Liao C, Song H, Yang SL, Xu WQ, Shi SW, Zhao N. Inflammatory cytokine measurement quickly discriminates gram-negative from gram-positive bacteremia in pediatric hematology/oncology patients with septic shock. Intensive Care Med. 2013;39(2):319-26.

44. Abe R, Oda S, Sadahiro T, Nakamura M, Hirayama Y, Tateishi $\mathrm{Y}$, et al. Gram-negative bacteremia induces greater magnitude of inflammatory response than Gram-positive bacteremia. Critical Care 2010;14:1-7. 
45. Arai T1, Ohta S2, Tsurukiri J2, Kumasaka K2, Nagata K2, Okita T, et al. Procalcitonin levels predict to identify bacterial strains in blood cultures of septic patients. Am J Emerg Med. 2016;34(11):2150-2153.

46. Feezor RJ, Oberholzer C, Baker HV, Novick D, Rubinstein M, Moldawer LL, et al. Molecular characterization of the acute inflammatory response to infections with gram-negative versus gram-positive bacteria. Infect Immun. 2003;71(10):5803-5813.

47. Foster TJ. The remarkably multifunctional fibronectin binding proteins of Staphylococcus aureus. Eur J Clin Microbiol Infect Dis. 2016. [Epub ahead of print]. Disponible en: https://www. ncbi.nlm.nih.gov/pubmed/27604831
48. Carrillo R.C, Tapia J, Peña C.A, Kim Kohd M.J, Jaime A.R, Montalvo E. Bases moleculares de la sepsis. Revista de la Facultad de Medicina de la UNAM. 2014;57(3):1-13.

49. Brosnahan AJ, Schlievert PM. Gram-positive bacterial superantigen outside-in signaling causes toxic shock syndrome. FEBS J. 2011;278(23):4649-67.

50. Briceño I. Sepsis: Etiología, Manifestaciones Clínicas y Diagnóstico. Medicrit 2005; 2(9):203-213.

51. Latini R, Caironi P, Masson S. Cardiac dysfunction and circulating cardiac markers during sepsis. Minerva Anestesiol. 2016;82(6):697-710. 